\title{
Reseña \\ never \\ Gené, M. (2019). La rosca política. El oficio de los armadores delante y detrás de escena (o el discreto encanto del toma $y$ daca). Siglo XXI Editores, 270 pp.
}

Iván Federico Basewicz Rojana ${ }^{1}$

Fecha de recepción: 24 de abril de 2020

Fecha de aceptación: 7 de mayo de 2020

\section{Resumen}

A partir del caso del Ministerio del Interior en Argentina entre 1983 y 2007, la socióloga e investigadora Mariana Gené busca abordar el estudio de la profesión política. Esto es realizado desde una doble perspectiva: la ministerial y la de los agentes. Por ello, la metodología utilizada corresponde con un enfoque prosopográfico propio de los estudios cualitativos. En este sentido, la diversidad de fuentes aporta un enriquecimiento y profundidad a la temática trabajada. En definitiva, resulta un texto fundamental para la comprensión y el estudio de las clases dirigentes.

Palabras clave: Ministerio del Interior, trayectoria, credenciales, política.

\section{Abstract}

Based on the case of the Ministry of the Interior in Argentina between 1983 and 2007, the sociologist and researcher Mariana Gené seeks to study the political profession. This is done from a double perspective: the ministerial and the agents. Therefore, the methodology used corresponds to a prosopographic approach specific to qualitative studies. In this sense, the diversity of sources brings an enrichment and depth to the thematic work. In short, it is a fundamental text for the understanding and study of the ruling classes.

Keywords: Ministry of Interior, trajectory, credentials, politics.

1- Nacionalidad: Argentina. Grado: Licenciado en Sociología. Institución: Universidad de Buenos Aires. (DORCID: http:// orcid.org/0000-0001-8019-0091. Correo electrónico: ibasewicz@sociales.uba.ar 
"Mientras otros ministerios regulan áreas de la vida social más delimitadas ... este se ocupa de articular relaciones e intereses ... procurar gobernabilidad” (p. 13). En La rosca política. El oficio de los armadores delante y detrás de escena (o el discreto encanto del toma y daca) la socióloga e investigadora Mariana Gené se sitúa en el Ministerio del Interior de Argentina entre 1983 y 2007 para interrogar la profesión política. Esta selección es sustentada sobre la base de que dicha cartera centraliza las negociaciones de los actores políticos de distintas escalas. De este modo, propone un doble foco: sobre el ministerio y sus elencos jerárquicos. En consecuencia, la propuesta metodológica remite a un estudio prosopográfico cuyas fuentes son entrevistas con los actores, notas periodísticas de los periódicos con mayor tirada en el país y archivos audiovisuales compilados en el Instituto de Investigaciones Gino Germani.

El texto se estructura en dos grandes apartados. El primero remite al estudio de los agentes que habitaron el ministerio, en tanto, la segunda parte hace referencia sobre las distintas gestiones desde el retorno democrático. En este sentido, el primer capítulo aborda los procesos de socialización políticas y las redes que genera. El segundo, toma como eje las distintas prácticas compartidas. Ya en la segunda mitad del libro, del tercer al sexto apartado son desarrollados los gobiernos de Raúl Alfonsín (1983-1989), Carlos Menem (1989-1999), Fernando De la Rúa (1999-2001) y los sucesos posteriores al estallido social del 2001 y la llegada de Néstor Kirchner a la presidencia de la Nación (2003-2007), respectivamente.

En tono con lo expuesto, primeramente, el estudio se focaliza en el ingreso a la política. Esta opera por dos vías: la pertenencia a una familia con tradición política o el comienzo en la militancia a partir de la vivencia de períodos históricos intensos (tales como los golpes de Estado de 1955, 1962, 1966 o 1976) que funcionan como "ciclos de politización" (p. 40). A partir de las redes de pertenencia generadas con aquellos con los que se tiene afinidad política es que se explica gran parte del acceso a cargos tanto electivos como no. La vinculación con "mentores y padrinos juega un rol fundamental en su entrada y permanencia en la carrera política" (p. 58). Los primeros son aquellos que suscitan un mayor compromiso político en los actores, en tanto, los segundos muestran una mayor incidencia en el desarrollo de sus futuras carreras, ya sea proveyendo contactos, encuadramiento o cercanía con la toma de decisiones. De esta manera, en dicha cartera priman los políticos "altamente profesionalizados" (p. 68).

Asimismo, existen ciertos recursos y competencias valorados dentro del ámbito ministerial. Una de las principales credenciales es la confianza presidencial, la posibilidad de que sus resoluciones no deban ser consultadas a este. Por otra parte, debe contar con familiaridad con el mundo de la política, comprender y manejar los distintos sistemas de relaciones que la componen para convertirse en un ávido negociador. Por último, la capacidad de "desplegar estrategias ... en momentos de crisis ..." (p. 117).

Tras la exposición teórica, es realizado un análisis de los ministros para el período comprendido en la investigación. El primero de ellos es Antonio Tróccoli, jefe de la cartera en los primeros años de la presidencia de Raúl Alfonsín. Este no mantenía una relación de confianza plena con el jefe de Estado, aunque su larga experiencia partidaria y paso por múltiples cargos electivos fue aquello que impulsó su designación. En un momento donde las responsabilidades penales por el terrorismo de Estado estaban en disputa, las relaciones con las fuerzas armadas y de seguridad constituyeron el eje principal de su gestión. En este sentido, uno de sus hitos de gestión fue la elaboración del informe de la Comisión Nacional sobre la Desaparición de Personas (CONADEP). Sin embargo, sería reemplazado por Enrique Nosiglia tras el fracaso radical en las elecciones legislativas de 1987. En un período signado por la inestabilidad institucional y económica, este se centró en dos reclamos históricos, la sanción de una nueva Ley de Co- 
participación y de Reordenamiento Sindical, siendo esta infructuosa. Su última labor sería la gestión de la asunción anticipada de Carlos Menem a la presidencia.

En sintonía con lo anterior, los primeros ministros del justicialismo fueron Eduardo Bauzá, Julio Mera Figueroa y José Luis Manzano, quienes debieron afrontar una coyuntura marcada por la hiperinflación heredada del período precedente. Sin embargo, los sucesivos escándalos de corrupción llevaron a Gustavo Beliz al frente de la cartera, siendo el más joven en asumir el cargo en todo el período estudiado. La corta duración de este en el cargo remite a que "su cuestionamiento de las prácticas fraudulentas requería mayor poder político y aliados para llegar a buen puerto" (p, 164). De este modo, asumirían sucesivamente dos ministros de confianza presidencial. Carlos Ruckauf tuvo como elemento distintivo las negociaciones por la reforma constitucional de 1994, la cual posibilitó la reelección del jefe de Estado, posteriormente acompañaría a Carlos Menem en la fórmula presidencial; en tanto Carlos Corach sería el de mayor duración en cargo y quien imprimiría una impronta distintiva a su gestión. “... conjugaba la autoridad y la claridad para las decisiones con la intuición política para acertar en situaciones de incertidumbre" (p. 171). Esto permitió garantizar la gobernabilidad en momentos de profundización de la crisis del modelo económico.

En el anteúltimo capítulo, toma lugar el análisis de los ministros de la Alianza para el Trabajo, la Justicia y la Educación comandada por Fernando De la Rúa. Frente a la problemática de erigirse en una buena coalición de gobierno, la cartera fue asignada a un referente histórico de la bancada radical, Federico Storani. Los mayores desafíos orbitaban en torno a la relación del Poder Ejecutivo y las provincias, quienes veían empeorar todos sus indicadores sociales, siendo el bautismo de fuego la intervención de la provincia de Corrientes en 1999; y el vínculo en el Congreso Nacional donde el oficialismo se constituía como minoría. Debido al renombrado escándalo de las "coimas en el Senado", asumía el ministerio Ramón Mestre quien fuera encargado de "administrar el ajuste" (p. 194). De esta manera terminaba la efímera experiencia aliancista.

Finalmente, el último apartado aborda los sucesos posteriores a la crisis de fines del 2001. Las cortas gestiones de Miguel Ángel Toma, Rodolfo Gabrielli y Jorge Matzkin buscaron garantizar el orden interno en aras de favorecer la realización de nuevas elecciones. Estas sucedieron en mayo de 2003 e implicaron un cambio sustancial en la configuración del Ministerio del Interior tras la llegada de Néstor Kirchner a la cabeza del Poder Ejecutivo. La designación de un referente del peronismo bonaerense de peso como fue Aníbal Fernández se vio opacada por la gestión de Alberto Fernández en la Jefatura de Gabinete, quien era señalado como una de las figuras centrales en la recuperación económica. De este modo, quedaba consolidada una menor importancia del ministerio político, una tendencia iniciada ya a inicios de la década.

A modo de conclusión, estamos ante un texto referencial para los académicos y los interesados en el campo de la politología y la sociología política. Un trabajo que cubre un vacío existente en el estudio de las clases dirigentes y, de ahí, su sustancialidad. 

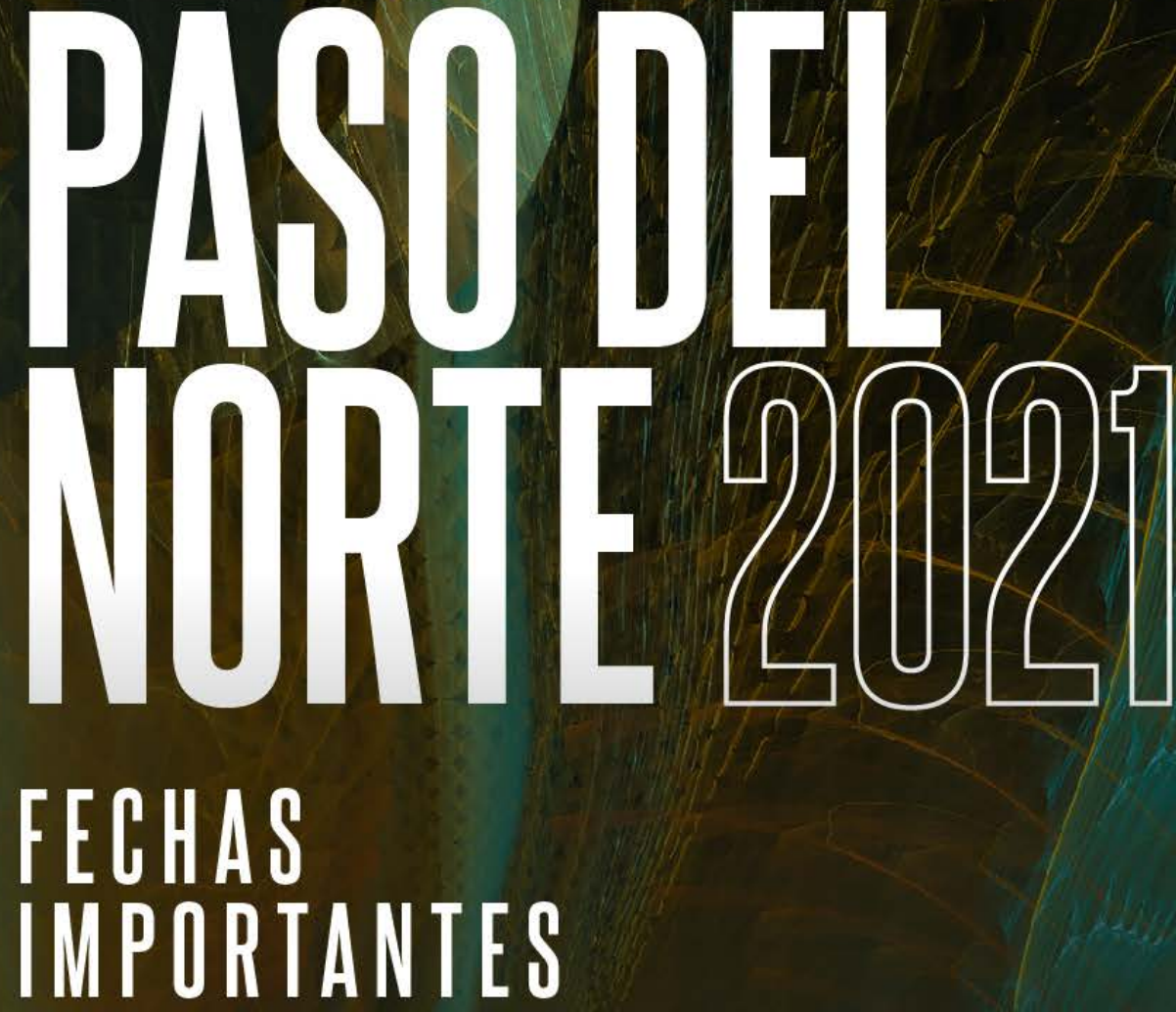

Recepción de trabajo

Del 15 de febrero al 7 de junio

Publicación de propuestas aceptadas 30 de julio

\begin{tabular}{ll}
\hline Fecha límite envío ponencias in extenso & $\mathbf{3 0}$ de septiembre \\
\hline Fecha límite de inscripción para ponentes & $\mathbf{8}$ de octubre \\
\hline Publicación del programa del Congreso & $\mathbf{2 2}$ de octubre \\
\hline Realización del Congreso & del $\mathbf{8}$ al $\mathbf{1 1}$ de noviembre \\
\hline Fecha límite para trámite de constancias & $\mathbf{3 0}$ de noviembre
\end{tabular}

Fecha límite para trámite de constancias

30 de noviembre

Registro de trabajos:

http://info.uacj.mx/congresocs2021 